\title{
The impact of benzodiazepines on occurrence of pneumonia and mortality from pneumonia: a nested case-control and survival analysis in a population-based cohort
}

\author{
Eneanya Obiora, ${ }^{1}$ Richard Hubbard, ${ }^{1}$ Robert D Sanders, ${ }^{2,3}$ Puja R Myles ${ }^{1}$
}

\begin{abstract}
- Additional supplementary
files are published online only. To view these files please visit the journal online (http://dx. doi.org/10.1136/thoraxjn2012-202374)

${ }^{1}$ Division of Epidemiology and Public Health, University of Nottingham, Nottingham, UK ${ }^{2}$ Department of Leucocyte Biology and Anaesthetics, Intensive Care and Pain Medicine, Imperial College London, London, UK ${ }^{3}$ Wellcome Department of Imaging Neuroscience, University College London, London, UK
\end{abstract}

\section{Correspondence to} Dr Robert D Sanders, Wellcome Department of Imaging Neuroscience, Institute of Cognitive Neuroscience, London, WCIN 3AR, UK; r.sanders@ucl.ac.uk

RDS and PRM contributed equally to this work.

Received 3 July 2012 Revised 18 September 2012 Accepted 5 October 2012 Published Online First 5 December 2012

\section{ABSTRACT \\ Objectives Benzodiazepines have been associated with an increased incidence of infections, and mortality from sepsis, in the critically ill. Here, we determined the effect of community use of benzodiazepines on the occurrence of, and mortality following, pneumonia.}

Methods A nested case-control study using 29697 controls and 4964 cases of community-acquired pneumonia (CAP) from The Health Improvement Network, a UK primary care patient database (20012002), investigated the association between benzodiazepines and pneumonia occurrence using conditional logistic regression. Cox regression was then used to determine the impact of benzodiazepines on mortality in the 4964 cases of CAP. Results are presented as adjusted OR, adjusted $\mathrm{HR}$ and $95 \% \mathrm{Cl}$.

Results Exposure to benzodiazepines was associated with an increased risk of pneumonia (OR 1.54, 95\% Cl 1.42 to 1.67$)$. Individually diazepam, lorazepam and temazepam, but not chlordiazepoxide, were associated with an increased incidence of CAP. As a class, benzodiazepines were associated with increased 30-day (HR $1.22(95 \% \mathrm{Cl} 1.06$ to 1.39)) and long-term mortality (HR $1.32(95 \%$ Cl 1.19 to 1.47$)$ ) in patients with a prior diagnosis of CAP. Individually diazepam, chlordiazepoxide, lorazepam and temazepam affected long-term mortality in these patients.

Conclusions Benzodiazepines were associated with an increased risk of, and mortality from, CAP. These hypothesis generating data suggest further research is required into the immune safety profile of benzodiazepines.

\section{INTRODUCTION}

In the UK and USA, approximately $2 \%$ of the population have taken benzodiazepines for 12 months or more ${ }^{1}$ and their use is even more prevalent in the elderly patients (up to $10 \%$ ). ${ }^{2}$ Benzodiazepines are widely used for anxiety, epilepsy, muscle spasm, alcohol withdrawal, palliation, insomnia and to provide sedation. These clinical effects are transduced by activation of inhibitory $\gamma$-amino butyric acid type A receptors $\left(\mathrm{GABA}_{\mathrm{A}}\right)$ in the brain.

Little is known about the immune effects of benzodiazepines. Animal studies suggest that diazepam increases susceptibility to infection, including pneumonia, ${ }^{3-7}$ perhaps via activation of $\mathrm{GABA}_{\mathrm{A}}$

\section{Key messages}

What is the key question?

- Do benzodiazepines increase the occurrence of, or mortality from, pneumonia?

What is the bottom line?

- Benzodiazepine exposure was associated with an increased risk of developing pneumonia and dying from pneumonia.

\section{Why read on?}

- Our data indicate a significant risk of benzodiazepine exposure on infectious lung disease which may be considered a modifiable risk factor in future studies.

receptors on immune cells. ${ }^{7}$ Limited clinical data support a hypothesis that benzodiazepines increase susceptibility to infection. It has been shown that avoidance of benzodiazepine sedation (lorazepam) by use of a non-GABAergic sedative improves survival in critically ill septic patients by $70 \%{ }^{8}{ }^{9}$ A similar study showed that sedation with the benzodiazepine midazolam doubled the risk of secondary infections in critically ill patients compared with non-GABAergic sedation. ${ }^{10}$ However, a more recent study did not observe the difference in infection rates. ${ }^{11}$ Furthermore, these studies used high doses of benzodiazepines to achieve sedation and so it is unclear whether these data have relevance to community use of these drugs.

The influence of subsedative doses of benzodiazepines on infectious outcomes is also incompletely evaluated in humans. One group reported that benzodiazepines and/or antidepressants increase mortality from pneumonia in over 60 -year-olds ${ }^{12}$ but not over 80 -year-olds. ${ }^{13}$ Additionally, a randomised controlled trial of diazepam therapy for acute stroke reported an increased incidence of pneumonia with diazepam treatment. ${ }^{14}$ In contrast, another group has suggested that benzodiazepines may be associated with a decreased incidence of pneumonia; however, this study used questionnaires to determine drug exposure and thus is prone to recall and reporting bias. ${ }^{15}$ A case-control study of patients over 65-years-old also did not report an 
increased risk of pneumonia with exposure to benzodiazepines though they report wide CI due at least in part to the low numbers of patients taking benzodiazepines in this study. ${ }^{16}$ Furthermore, all these studies were small and the outcomes varied and limited; for example, currently it is unclear whether there is any long-term effect on mortality.

We hypothesised that benzodiazepines would increase the odds of pneumonia and mortality from pneumonia. We also performed analyses of the non-benzodiazepine, zopiclone, as it also acts by activation of $\mathrm{GABA}_{\mathrm{A}}$ receptors but lacks many of the other molecular effects of benzodiazepines. ${ }^{17}$ Testing zopiclone was intended to provide preliminary information about the safety of GABAergic drugs as a group. We focus here on the risk of pneumonia, and 30-day and long-term mortality from pneumonia.

\section{METHODS}

The Health Improvement Network (THIN) database is a large, longitudinal collection of records of patients registered to various primary care facilities all over the UK. This contains about 9.1 million registered patients, of which 3.4 million are categorised as 'active patients'. ${ }^{18}$ Data are entered using Read codes that map onto the International Classification of Disease-9 codes. Ethical approval for this study was obtained from the Scientific Review Committee (SRC) (11-010R). We conducted two analytical studies within the THIN populationbased cohort: (i) a matched nested case-control analysis to address whether the occurrence of pneumonia was associated with benzodiazepine exposure using conditional logistic regression and (ii) a survival analysis using Cox regression to investigate the association of benzodiazepine exposure with mortality in pneumonia patients.

Cases were patients of all ages in the database with a diagnosis of pneumonia as identified by the patient's medical records occurring between 1 July 2001 and 1 July 2002. We used only the first recorded pneumonia diagnosis within this period for each case. This ensured that only 'incident' cases were picked. Identification of cases was done using specific medical Read codes corresponding to a pneumonia diagnosis (available on request) with a designated index date. For each case, six controls were matched by practice, sex and age at index date (within 3 years). The generally accepted rule is that more than four to five controls rarely add to the efficiency of a study. We included six controls because the cost of including additional controls is negligible (an advantage provided by THIN), and there is concern for sufficient numbers in stratified analyses. ${ }^{19}$ Both cases and controls required at least a year's worth of prior data to be included in the study to allow for adequate capture of confounding variables. We did not exclude controls or cases if they had a recorded pneumonia diagnosis before our selected study period and included previous pneumonia episodes as a covariate in our analyses.

All recorded prescriptions of benzodiazepines and zopiclone were used. Exposure to drug was classified as 'current' when the most recent prescription was within 30 days before the pneumonia index date. Prescriptions within 31-90 days before the index were treated as 'recent' exposures, while prescriptions of 90 days or more before the index date were treated as 'past' exposure. An additional category was created for 'no use' where subjects had never been prescribed any benzodiazepine. These categories were determined by the British National Formulary prescription guidelines and confirmed by plotting histograms to check prescription lengths and patterns. A supplementary analysis was conducted to understand the odds of pneumonia in patients who were chronically on benzodiazepines. These patients were defined as having prescriptions both in the 30and 90-day periods before the pneumonia event date.

We evaluated the following comorbidities as potential confounders: ischaemic heart disease, pulmonary disease (including chronic obstructive pulmonary disease and asthma) and previous pneumonia episodes. In addition, we used a combined weighted comorbidity index, the Charlson index adapted for use with International Classification of Disease-9 codes. $^{20} 21$ Other potential confounders considered include alcohol consumption (categorised as above or at/below recommended weekly units for both male and female subjects), diagnosis of depression and psychosis, current smoking (the most recent record of smoking status was used) and socioeconomic status measured using the Townsend deprivation score quintiles (the first quintile being the least deprived, while the fifth quintile being the most deprived). ${ }^{22}$

Conditional logistic regression was used to investigate the association between exposure to the different drugs and risk of pneumonia. Cox regression was used to assess the association between drug exposure and mortality following confirmation that the proportional hazard assumptions were met. Two mortality endpoints were investigated, 30-day and long-term mortality. Our primary interest was the effect of benzodiazepines as a group on the occurrence of, and mortality following, pneumonia. However, we also looked at the effects of individual benzodiazepines and zopiclone. Results have been expressed as OR or HR with 95\% CI. The multivariable model included all variables that were either a significant risk factor for pneumonia in the univariate analysis $(p<0.05)$ or were found to modify the OR for drug association by at least $10 \%$ when included in a model with the main exposure variable. Given that age, comorbidity $^{12}{ }^{13}$ and gender ${ }^{23}$ may influence the effect of benzodiazepines, we tested for interactions among benzodiazepines and age, gender or Charlson comorbidity status. All analyses were carried out in Stata11. ${ }^{24}$ The data are reported in accordance with STROBE guidance.

\section{RESULTS}

The sample used in this research had a total of 34661 patients, of whom there were 29697 controls and 4964 cases. The characteristics of cases and controls are summarised in table 1 . Cases were more likely to have had previous episodes of pneumonia, myocardial infarction, a history of depression, a history of psychosis related diagnosis, be current smokers and have a higher Charlson's comorbidity index score as compared with controls.

\section{Benzodiazepines and risk of pneumonia}

Table 2 shows the adjusted and unadjusted OR for benzodiazepine as a class, and as individual benzodiazepines. After adjusting for current smoking, presence of lung disease, Townsend deprivation index, diagnosis of depression or psychosis, Charlson's comorbidity index, myocardial infarction and previous episode of pneumonia a significant association was seen between benzodiazepine use and increase in pneumonia risk (adjusted OR $1.54,95 \%$ CI 1.42 to 1.67$)$. After adjustment for confounders, prescriptions of diazepam, lorazepam and temazepam were associated with an increased risk of pneumonia (table 2). However, we did not find a statistically significant association between current use of chlordiazepoxide and pneumonia risk (table 2). Furthermore, use of zopiclone, a non-benzodiazepine drug acting on $\mathrm{GABA}_{\mathrm{A}}$ receptors, similarly showed a higher risk of pneumonia (table 2). Refinement of the analysis to look at 
current prescriptions showed that diazepam, temazepam and zopiclone were all associated with higher odds of pneumonia. A supplementary analysis was conducted to understand the odds of pneumonia in patients who were chronically on benzodiazepines. These patients were defined as having prescriptions both in the 30- and 90-day periods before the pneumonia event date. They were compared with non-benzodiazepine users. Chronic users represented the majority of the cohort and therefore it is unsurprising that the results were similar in this analysis to the primary analysis (see online supplementary table 1a).

A test for interaction was carried out with age, gender and Charlson's comorbidity index score for the main drug exposure, benzodiazepine use. No interactions were found with age or gender for drug exposure; however, a statistically significant interaction was found by Charlson's comorbidity index score $(\mathrm{p}<0.001)$. Table 3 shows the stratified analysis results. The association between benzodiazepine use and pneumonia incidence was stronger in people with lower comorbidity scores.

\section{Benzodiazepines and mortality following pneumonia}

We next analysed whether benzodiazepine exposure increased long-term mortality (median follow-up 2.8 years) following pneumonia and found that current and recent prescriptions exerted the greatest effect (table 4). Individually all drugs tested, except zopiclone, were associated with higher long-term mortality. However, 30-day mortality was only affected by diazepam

Table 1 Characteristics of cases and controls $(n=34661)$

\begin{tabular}{|c|c|c|c|}
\hline Characteristics & Controls $(n=29697)$ & Cases $(n=4964)$ & Unadjusted OR $(95 \% \mathrm{Cl})$ \\
\hline \multicolumn{4}{|l|}{ Age (years) } \\
\hline$<25$ & $4598(15.48 \%)$ & $766(15.43 \%)$ & \multirow[t]{4}{*}{ Matching variable } \\
\hline $25-50$ & $5585(18.81 \%)$ & $932(18.78 \%)$ & \\
\hline $51-75$ & $10082(33.95 \%)$ & $1675(33.74 \%)$ & \\
\hline$>75$ & $9432(31.7 \%)$ & $1591(32.05 \%)$ & \\
\hline \multicolumn{4}{|l|}{ Sex } \\
\hline Male & $13760(46.33 \%)$ & $2304(46.41 \%)$ & \multirow[t]{2}{*}{ Matching variable } \\
\hline Female & $15937(53.67 \%)$ & $2660(53.59 \%)$ & \\
\hline \multicolumn{4}{|l|}{ Current smokers } \\
\hline No & $24591(82.81 \%)$ & $3745(75.44 \%)$ & 1.00 \\
\hline Yes & $5106(17.19 \%)$ & $1219(24.56 \%)$ & $1.69(1.57 \text { to } 1.83)^{*}$ \\
\hline \multicolumn{4}{|l|}{ Previous pneumonia } \\
\hline No & $28935(97.43 \%)$ & $4518(91.02 \%)$ & 1.00 \\
\hline Yes & $762(2.57 \%)$ & $446(8.98 \%)$ & $4.04(3.56 \text { to } 4.59)^{*}$ \\
\hline \multicolumn{4}{|c|}{ Townsend score deprivation quintile } \\
\hline 1 (least deprived) & $6546(22.04 \%)$ & $983(19.80 \%)$ & 1.00 \\
\hline 2 & $6408(21.58 \%)$ & $973(19.60 \%)$ & $1.02(0.93$ to 1.13$)$ \\
\hline 3 & $5541(18.66 \%)$ & $947(19.08 \%)$ & $1.18(1.07$ to 1.31$)$ \\
\hline 4 & $5132(17.28 \%)$ & $904(18.21 \%)$ & 1.24 (1.12 to 1.38$)$ \\
\hline \multirow[t]{3}{*}{5 (most deprived) Missing } & $3971(13.37 \%)$ & $781(15.73 \%)$ & $1.42(1.27$ to 1.60$)$ \\
\hline & $2099(7.07 \%)$ & $376(7.57 \%)$ & - \\
\hline & & & $p$ trend $<0.001$ \\
\hline \multicolumn{4}{|l|}{ Myocardial infarction } \\
\hline No & 26757 (90.10\%) & $4334(87.31 \%)$ & 1.00 \\
\hline Yes & $2940(9.90 \%)$ & $630(12.69 \%)$ & $1.36(1.23 \text { to } 1.50)^{*}$ \\
\hline \multicolumn{4}{|c|}{ Charlson's comorbidity index score } \\
\hline 0 & $17303(58.27 \%)$ & $1939(39.06 \%)$ & 1.00 \\
\hline $1-2$ & $9173(30.89 \%)$ & $1964(39.56 \%)$ & 2.27 (2.11 to 2.44$)$ \\
\hline $3-5$ & $2997(10.09 \%)$ & $929(18.71 \%)$ & 3.74 (3.38 to 4.13$)$ \\
\hline \multirow[t]{2}{*}{$>5$} & $224(0.75 \%)$ & $132(2.66 \%)$ & 7.43 (5.91 to 9.34$)$ \\
\hline & & & $p$ trend $<0.001$ \\
\hline \multicolumn{4}{|l|}{ Depression } \\
\hline No & $26380(88.83 \%)$ & $4123(83.06 \%)$ & 1.00 \\
\hline Yes & $3317(11.17 \%)$ & $841(16.94 \%)$ & $1.71(1.57 \text { to } 1.87)^{*}$ \\
\hline \multicolumn{4}{|l|}{ Psychosis } \\
\hline No & $29565(99.56 \%)$ & $4930(99.32 \%)$ & 1.00 \\
\hline Yes & $132(0.44 \%)$ & $34(0.68 \%)$ & 1.54 (1.06 to 2.25$)$ \\
\hline \multicolumn{4}{|l|}{ Alcohol } \\
\hline Below limit & $18308(61.65 \%)$ & $3137(63.20 \%)$ & 1.00 \\
\hline Above limit & $11389(38.35 \%)$ & $1827(36.80 \%)$ & 0.90 (0.83 to 0.98$)$ \\
\hline \multicolumn{4}{|l|}{ Lung diseases } \\
\hline No & $26493(89.21 \%)$ & $3763(75.81 \%)$ & 1.00 \\
\hline Yes & $3204(12.44 \%)$ & $1201(24.19 \%)$ & $2.74(2.54 \text { to } 2.96)^{*}$ \\
\hline
\end{tabular}

Statistically significant $(p \leq 0.05)$ results are in bold. ${ }^{*} \mathrm{p}<0.001$. 
Table 2 Association between benzodiazepine and zopiclone exposure and the incidence of pneumonia (case-control study)

\begin{tabular}{|c|c|c|c|c|c|c|}
\hline Exposure variable & Cases $(n=4964)$ & Controls ( $n=29697)$ & Unadjusted OR (95\% CI) & $p$ Value & Adjusted OR $(95 \% \mathrm{Cl})^{*}$ & $\mathrm{p}$ Value \\
\hline \multicolumn{7}{|l|}{ Benzodiazepines } \\
\hline No & $3695(74.44 \%)$ & $25071(84.42 \%)$ & 1.00 & & 1.00 & \\
\hline Yes & $1269(25.56 \%)$ & $4626(15.58 \%)$ & 2.00 (1.85 to 2.16$)$ & $<0.001$ & 1.54 (1.42 to 1.67$)$ & $<0.001$ \\
\hline \multicolumn{7}{|l|}{ Benzodiazepines } \\
\hline Current & $328(6.61 \%)$ & $976(3.29 \%)$ & 2.53 (2.21 to 2.89$)$ & & 1.89 (1.64 to 2.18$)$ & \\
\hline Recent & $145(2.92 \%)$ & $433(1.46 \%)$ & 2.49 (2.05 to 3.03$)$ & $p$ trend & 1.95 (1.58 to 2.39 ) & $p$ trend \\
\hline Past & $796(16.04 \%)$ & $3217(10.83 \%)$ & 1.79 (1.64 to 1.96$)$ & $<0.001$ & 1.39 (1.27 to 1.53$)$ & $<0.001$ \\
\hline \multicolumn{7}{|l|}{ Diazepam } \\
\hline No & $4321(87.05 \%)$ & $27505(92.62 \%)$ & 1.00 & & 1.00 & \\
\hline Yes & $643(12.95 \%)$ & $2192(7.38 \%)$ & 1.93 (1.76 to 2.13 ) & $<0.001$ & 1.49 (1.34 to 1.65$)$ & $<0.001$ \\
\hline \multicolumn{7}{|l|}{ Diazepam } \\
\hline Current & $103(2.07 \%)$ & $243(0.82 \%)$ & 2.81 (2.22 to 3.55$)$ & & 2.11 (1.64 to 2.71$)$ & \\
\hline Recent & $49(0.99 \%)$ & $151(0.51 \%)$ & 2.12 (1.53 to 2.93$)$ & $p$ trend & 1.60 (1.14 to 2.25$)$ & $p$ trend \\
\hline Past & $491(9.89 \%)$ & 1798 (6.05\%) & 1.80 (1.62 to 2.01$)$ & $<0.001$ & 1.39 (1.24 to 1.56$)$ & $<0.001$ \\
\hline \multicolumn{7}{|l|}{ Lorazepam } \\
\hline No & $4891(98.53 \%)$ & $29495(99.32 \%)$ & 1.00 & & 1.00 & \\
\hline Yes & $73(1.47 \%)$ & $202(0.68 \%)$ & 2.20 (1.68 to 2.89 ) & $<0.001$ & 1.65 (1.24 to 2.20$)$ & 0.001 \\
\hline \multicolumn{7}{|l|}{ Lorazepam } \\
\hline Current & $21(0.42 \%)$ & $63(0.21 \%)$ & 2.01 (1.22 to 3.31$)$ & & 1.66 (0.98 to 2.81$)$ & \\
\hline Recent & $8(0.16 \%)$ & $21(0.07 \%)$ & 2.36 (1.04 to 5.37$)$ & $\mathrm{p}$ trend & 1.76 (0.74 to 4.18$)$ & $\mathrm{p}$ trend \\
\hline Past & $44(0.89)$ & $118(0.40 \%)$ & 2.28 (1.61 to 3.23$)$ & $<0.001$ & $1.63(1.13$ to 2.35$)$ & 0.002 \\
\hline \multicolumn{7}{|l|}{ Chlordiazepoxide } \\
\hline No & 4901 (98.73\%) & $29460(99.20 \%)$ & 1.00 & & 1.00 & \\
\hline Yes & $63(1.27 \%)$ & $237(0.80 \%)$ & 1.62 (1.22 to 2.15$)$ & 0.001 & 1.19 (0.88 to 1.62$)$ & 0.248 \\
\hline \multicolumn{7}{|l|}{ Chlordiazepoxide } \\
\hline Current & $10(0.20 \%)$ & $31(0.10 \%)$ & 1.94 (0.95 to 3.95$)$ & & 1.51 (0.71 to 3.23 ) & \\
\hline Recent & $7(0.14 \%)$ & $14(0.05 \%)$ & 3.01 (1.22 to 7.46$)$ & $\mathrm{p}$ trend & 2.65 (1.03 to 6.77$)$ & $\mathrm{p}$ trend \\
\hline Past & $46(0.93 \%)$ & $192(0.65 \%)$ & 1.46 (1.05 to 2.03$)$ & 0.004 & 1.04 (0.74 to 1.48 ) & 0.445 \\
\hline \multicolumn{7}{|l|}{ Temazepam } \\
\hline No & $4310(86.83 \%)$ & $27391(92.23 \%)$ & 1.00 & & 1.00 & \\
\hline Yes & $654(13.17 \%)$ & $2306(7.77 \%)$ & $1.87(1.70$ to 2.06$)$ & $<0.001$ & $1.43(1.29$ to 1.59$)$ & $<0.001$ \\
\hline \multicolumn{7}{|l|}{ Temazepam } \\
\hline Current & $149(3.00 \%)$ & $459(1.55 \%)$ & 2.20 (1.81 to 2.66$)$ & & 1.69 (1.38 to 2.06$)$ & \\
\hline Recent & $66(1.33 \%)$ & $185(0.62 \%)$ & $2.40(1.79$ to 3.20$)$ & $\mathrm{p}$ trend & 1.90 (1.41 to 2.57$)$ & $\mathrm{p}$ trend \\
\hline Past & $439(8.84 \%)$ & $1662(5.60 \%)$ & 1.74 (1.55 to 1.94$)$ & $<0.001$ & 1.32 (1.17 to 1.49$)$ & $<0.001$ \\
\hline \multicolumn{7}{|l|}{ Zopiclone } \\
\hline No & $4883(98.37 \%)$ & $29512(99.38 \%)$ & 1.00 & & 1.00 & \\
\hline Yes & $81(1.63 \%)$ & $185(0.62 \%)$ & 2.68 (2.05 to 3.49$)$ & $<0.001$ & 1.98 (1.49 to 2.64$)$ & $<0.001$ \\
\hline \multicolumn{7}{|l|}{ Zopiclone } \\
\hline Current & $18(0.36 \%)$ & $36(0.12 \%)$ & $3.10(1.75$ to 5.48$)$ & & 2.07 (1.13 to 3.81$)$ & \\
\hline Recent & $7(0.14 \%)$ & $16(0.05 \%)$ & 2.38 (0.97 to 5.89 ) & $\mathrm{p}$ trend & 1.62 (0.61 to 4.31$)$ & $\mathrm{p}$ trend \\
\hline Past & $56(1.13 \%)$ & $133(0.45 \%)$ & 2.60 (1.89 to 3.57$)$ & $<0.001$ & 2.01 (1.43 to 2.81$)$ & $<0.001$ \\
\hline
\end{tabular}

Table 3 Association between benzodiazepines and incidence of pneumonia stratified by Charlson comorbidity index (CCI) score (case-control study)

\begin{tabular}{|c|c|c|c|c|}
\hline \multirow[b]{2}{*}{ Exposure variable } & \multicolumn{4}{|c|}{ Adjusted* OR (95\% Cl) stratified by CCI score } \\
\hline & $\mathrm{CCl}$ score 0 & CCI score 1-2 & CCI score $>3$ & $\mathrm{CCl}$ score $>5$ \\
\hline Benzodiazepine use & 1.98 (1.68 to 2.35$)$ & $1.46(1.26$ to 1.69$)$ & 1.09 (0.86 to 1.40$)$ & $-\dagger$ \\
\hline \multicolumn{5}{|l|}{ Benzodiazepine use } \\
\hline Current & 2.81 (2.02 to 3.90$)$ & 2.01 (1.54 to 2.62 ) & $0.77(0.52$ to 1.15$)$ & $-t$ \\
\hline Recent & $1.93(1.20$ to 3.11$)$ & 1.91 (1.29 to 2.83$)$ & 2.31 (1.31 to 4.09 ) & \\
\hline Past & 1.80 (1.48 to 2.19$)$ & 1.26 (1.07 to 1.50$)$ & 1.09 (0.81 to 1.46$)$ & \\
\hline
\end{tabular}

Reference category is 'no use'.

*Adjusted for Charlson's index score, Townsend score, depression, myocardial infarction, previous pneumonia, current smoke and lung disease; statistically significant results ( $p<0.05$ ) in bold.

tCould not be calculated due to insufficient data. 
Table 4 Association between 30-day and long-term mortality following pneumonia and benzodiazepine use, all ages (cohort study; $\mathrm{n}=4964$ )

\begin{tabular}{|c|c|c|c|c|c|c|}
\hline Drug & $\begin{array}{l}\text { Numbers dead at } \\
30 \text { days }(\%)(n=947)\end{array}$ & $\begin{array}{l}\text { 30-Day adjusted } \\
\mathrm{HR}^{*}(95 \% \mathrm{Cl})\end{array}$ & $p$ Value & $\begin{array}{l}\text { Long-term mortality }(\%) \\
(n=1547)\end{array}$ & $\begin{array}{l}\text { Long-term mortality } \\
\text { adjusted } \mathrm{HR}^{*}(95 \% \mathrm{CI})\end{array}$ & p Value \\
\hline \multicolumn{7}{|c|}{ Benzodiazepine } \\
\hline No & $568(15.4)$ & 1.00 & & $938(25.4)$ & 1.00 & \\
\hline Yes & $379(29.9)$ & $1.22(1.06$ to 1.39$) \dagger$ & 0.004 & $609(48.0)$ & $1.32(1.19$ to 1.47$)$ & $<0.001$ \\
\hline \multicolumn{7}{|c|}{ Benzodiazepine } \\
\hline Current & $123(37.5)$ & 1.35 (1.10 to 1.64$)$ & & $185(56.4)$ & 1.42 (1.21 to 1.67$)$ & \\
\hline Recent & $61(42.1)$ & 1.36 (1.04 to 1.79$)$ & $p$ trend & $93(64.1)$ & $1.49(1.19$ to 1.85$)$ & $\mathrm{p}$ trend \\
\hline Past & $195(24.5)$ & 1.12 (0.95 to 1.32 ) & 0.081 & $331(41.6)$ & $1.24(1.09$ to 1.41$)$ & $<0.001$ \\
\hline \multicolumn{7}{|l|}{ Diazepam } \\
\hline No & $781(18.1)$ & 1.00 & & $1279(29.6)$ & 1.00 & \\
\hline Yes & $166(25.8)$ & 1.24 (1.04 to 1.47$)$ & 0.014 & $268(41.7)$ & $1.27(1.11-1.46)$ & 0.001 \\
\hline \multicolumn{7}{|l|}{ Diazepam } \\
\hline Current & $40(38.8)$ & 2.00 (1.45 to 2.75$)$ & & 49 (47.6) & 1.71 (1.28 to 2.28$)$ & \\
\hline Recent & $16(32.7)$ & $1.48(0.90$ to 2.43$)$ & $p$ trend & $27(55.1)$ & 1.86 (1.27 to 2.73$)$ & $\mathrm{p}$ trend \\
\hline Past & $110(22.4)$ & 1.06 (0.87 to 1.30$)$ & 0.225 & $192(39.1)$ & $1.14(0.98-1.34)$ & $<0.001$ \\
\hline \multicolumn{7}{|c|}{ Chlordiazepoxide } \\
\hline No & $930(19.0)$ & 1.00 & & $1519(31.0)$ & 1.00 & \\
\hline Yes & $17(27.0)$ & 1.58 (0.98 to 2.57 ) & 0.063 & $28(44.4)$ & 1.49 (1.02 to 2.17$)$ & 0.038 \\
\hline \multicolumn{7}{|c|}{ Chlordiazepoxide } \\
\hline Current & $2(20.0)$ & 0.92 (0.23 to 3.69 ) & & $4(40.0)$ & 1.01 (0.38 to 2.70$)$ & \\
\hline Recent & $4(57.1)$ & 1.98 (0.74 to 5.34 ) & $p$ trend & $6(85.7)$ & 1.95 (0.87 to 4.37 ) & $p$ trend \\
\hline Past & $11(23.9)$ & 1.68 (0.93 to 3.06$)$ & 0.045 & 18 (39.1) & 1.53 (0.96 to 2.45$)$ & 0.030 \\
\hline \multicolumn{7}{|l|}{ Lorazepam } \\
\hline No & $913(18.7)$ & 1.00 & & $1502(30.7)$ & 1.00 & \\
\hline Yes & $34(46.9)$ & 1.61 (1.14 to 2.28$)$ & 0.007 & $45(61.6)$ & $1.48(1.10$ to 2.00$)$ & 0.010 \\
\hline \multicolumn{7}{|l|}{ Lorazepam } \\
\hline Current & $10(47.6)$ & 1.54 (0.82 to 2.88 ) & & $13(61.9)$ & 1.29 (0.75 to 2.24$)$ & \\
\hline Recent & $7(87.5)$ & 2.57 (1.21 to 5.47$)$ & $p$ trend & $8(100.0)$ & 2.79 (1.38 to 5.64$)$ & $\mathrm{p}$ trend \\
\hline Past & 17 (38.6) & 1.44 (0.89 to 2.33$)$ & 0.018 & $24(54.6)$ & 1.38 (0.92 to 2.06$)$ & 0.017 \\
\hline \multicolumn{7}{|c|}{ Temazepam } \\
\hline No & $738(17.1)$ & 1.00 & & $1209(28.1)$ & 1.00 & \\
\hline Yes & $209(32.0)$ & 1.11 (0.95 to 1.29$)$ & 0.208 & $338(51.7)$ & 1.20 (1.06 to 1.36$)$ & 0.003 \\
\hline \multicolumn{7}{|c|}{ Temazepam } \\
\hline Current & $46(30.9)$ & 0.91 (0.67 to 1.22 ) & & $85(57.1)$ & $1.12(0.90$ to 1.40$)$ & \\
\hline Recent & $29(43.9)$ & 1.12 (0.77 to 1.63$)$ & $p$ trend & $40(60.6)$ & $1.02(0.74$ to 1.40$)$ & $\mathrm{p}$ trend \\
\hline Past & $134(30.5)$ & 1.19 (0.99 to 1.44 ) & 0.071 & $213(48.5)$ & 1.28 (1.11 to 1.49$)$ & 0.001 \\
\hline \multicolumn{7}{|l|}{ Zopiclone } \\
\hline No & $932(19.1)$ & 1.00 & & $1517(31.1)$ & 1.00 & \\
\hline Yes & $15(18.5)$ & $0.92(0.55$ to 1.53$)$ & 0.738 & $30(37.0)$ & $1.11(0.77$ to 1.60$)$ & 0.564 \\
\hline \multicolumn{7}{|l|}{ Zopiclone } \\
\hline Current & $5(27.8)$ & 1.43 (0.59 to 3.44 ) & & $10(55.6)$ & 2.17 (1.17 to 4.06$)$ & \\
\hline Recent & $1(14.3)$ & 0.30 (0.04 to 2.12 ) & $p$ trend & $5(71.4)$ & 0.85 (0.35 to 2.04$)$ & $\mathrm{p}$ trend \\
\hline Past & $9(16.1)$ & 0.95 (0.49 to 1.83 ) & 0.641 & $15(26.8)$ & 0.91 (0.55 to 1.52 ) & 0.943 \\
\hline
\end{tabular}

Bold values indicate statistically significant results. All comparisons are in reference to 'no use'; percentages shown represent 'row' percentages, that is, the proportion of cases who died within each exposure category.

${ }^{*}$ Adjusted for age, sex, Townsend deprivation score, current smoking, Charlson comorbidity index score, alcohol use, depression and psychosis.

tThese data have been published previously, see reference. ${ }^{1}$

and lorazepam (table 4). When individual benzodiazepine use was divided by the timing of prescription, only current diazepam prescription appeared to influence mortality (table 4). Again, we conducted a supplementary analysis to understand whether the odds of death following pneumonia in patients who had prescriptions in 'chronic users' were different compared with those who did not take benzodiazepines. The results were similar and largely unchanged by this analysis (see online supplementary table $1 \mathrm{~b}$ ). A supplementary propensity score analysis based on the medical history was also conducted to help limit concerns over residual confounding. Using this technique, the results were largely the same; however, zopiclone also increased long-term mortality (see online supplementary table 1c). Using the whole dataset we also investigated whether the mortality effect of the class of benzodiazepines was affected by age, gender or comorbidity; similar to the effect on the incidence of pneumonia, we found that increasing comorbidity reduced the impact of benzodiazepines on mortality (table 5).

\section{DISCUSSION}

Herein we have demonstrated that benzodiazepine and zopiclone exposure was associated with an approximately $50 \%$ increase in risk of pneumonia with a similar associated increase in mortality from pneumonia. Interestingly, the non- 
Table 5 Association between benzodiazepines and all-cause mortality following a pneumonia diagnosis stratified by Charlson comorbidity index (CCI) score (reference category is no use; cohort study)

\begin{tabular}{|c|c|c|c|c|}
\hline \multirow[b]{2}{*}{ Exposure variable } & \multicolumn{4}{|c|}{ Adjusted* HR $(95 \% \mathrm{Cl})$ stratified by $\mathrm{CCl}$ score } \\
\hline & CCl score 0 & CCI score 1-2 & $\mathrm{CCl}$ score $>3$ & $\mathrm{CCl}$ score $>5$ \\
\hline Benzodiazepine use & 1.77 (1.34 to 2.33 ) & 1.28 (1.09 to 1.50$)$ & 1.25 (1.04 to 1.50$)$ & $1.13(0.73$ to 1.73$)$ \\
\hline \multicolumn{5}{|l|}{ Benzodiazepine use } \\
\hline Current & $1.96(1.34$ to 2.85$)$ & $1.30(1.01$ to 1.68$)$ & $1.34(1.00$ to 1.79$)$ & $1.26(0.70$ to 2.26$)$ \\
\hline Recent & 2.78 (1.61 to 4.79 ) & 1.33 (0.93 to 1.90$)$ & $1.29(0.90$ to 1.85$)$ & 2.15 (0.99 to 4.67$)$ \\
\hline Past & $1.45(1.00$ to 2.08$)$ & $1.26(1.04$ to 1.52$)$ & $1.21(0.98$ to 1.50$)$ & $0.89(0.51$ to 1.53$)$ \\
\hline
\end{tabular}

benzodiazepine zopiclone was associated with a higher risk of pneumonia. We adjusted for presence of lung disease in cases and controls, previous pneumonia, depression, myocardial infarction, socio-economic factors, comorbidity, alcohol use and smoking status. However we cannot exclude the effect of unmeasured confounding, though we have adjusted for many factors in this analysis. For example, while we have adjusted for psychiatric and medical comorbidities, we cannot exclude further confounding by indication. In order to better understand the benzodiazepine effect we investigated whether age, gender or comorbidity influenced the results, finding that increasing comorbidity reduced the impact of the drug on risk of pneumonia and mortality from pneumonia. Finally, we must stress that our data cannot be used to definitively link cause and effect, though the findings are in line with our hypothesis and preclinical data. Prospective cohort studies are now required to investigate our hypothesis further.

This is a large population-based case-control and cohort study with 29697 controls and 4946 cases. We have used THIN database that is representative of the UK population; previous results from research using THIN have been in keeping with research from other large databases. ${ }^{25}$ This makes our findings applicable to the general population and ensures no recall bias as exposures were recorded prospectively before the diagnosis of pneumonia. The mode of collection of data (ie, routinely, non-interventional and in a prospective manner prior to the diagnosis of pneumonia) also ensures that reporting bias is eliminated at the point of data collection. The prospective data collection ensures the avoidance of temporal bias as relating to the timing of the exposure to benzodiazepines. For the casecontrol study, cases and controls were individually matched by age, sex and location of practice, therefore, reducing the confounding effects of these variables. In particular, due to the prescribing policies and variations in different regions, matching by practice harmonises this factor.

A few limitations to our study should be highlighted. One is the possibility of selection bias; while we have adjusted for psychiatric and medical comorbidities, other patient factors associated with benzodiazepine use may account for the difference. Likewise, we cannot be totally confident that we have removed all residual confounders. Another possibility is an error of misclassification of pneumonia that may arise from differences in coding practices. While these data reflect infectious lung disease, ${ }^{26-28}$ and thus are adequate to investigate the effect of these drugs on a clinical infection, the absence of a confirmatory chest $\mathrm{x}$-ray questions the actual diagnosis of pneumonia. However, if this happens, the results would be biased towards unity because the misclassification should be independent of exposure status. Codes for 'acute lower respiratory tract infection' (ALRTI) have been included in the case definition as some cases of pneumonia may be coded as ALRTI in the absence of a confirmatory radiograph (see supplementary file). Nonetheless, our findings suggest that the clinical diagnosis of pneumonia and the associated mortality are both affected by the drugs. A related concern may be whether severity of pneumonia should be adjusted for; however, these data are not available within the dataset. Nonetheless, severity of pneumonia may well be dependent on exposure status to benzodiazepines (given that risk of, and mortality following, pneumonia appear to be dependent) and therefore even if the data on the severity of pneumonia were available it would not be sensible to adjust for this. In order to avoid counting a single case multiple times (eg, if the patient reconsults for the same episode of illness), only the first ever record of pneumonia diagnosis occurring within the study period was considered.

Differences in coding practices of some of the confounding variables might also bring in some form of bias in the study. However, this misclassification should be independent of exposure and outcome status; thus, bias will be non-differential. The Charlson's comorbidity index score is calculated by weighting disease burdens with mortality being the outcome; ${ }^{20} 2129$ however, the index has previously been validated in the literature for use in morbidity studies. ${ }^{20}{ }^{29}$ Furthermore, we augmented this index with further variables at our disposal to limit residual confounding. Another possible limitation it that we included covariates in the final model based on our initial bivariate analysis; this may be inferior to including all variables identified a priori.

Prescription data were used as a proxy for exposure to the drugs; however, we cannot be certain that the drugs were taken as recommended by the general practitioner. This might lead to an overestimation of exposure to these drugs in the analysis. This limitation, however, would be non-differential and would again bias the results towards unity (ie, reduce the benzodiazepine effect). However, analysis of 'chronic users' showed similar effects to the overall cohort (see online supplementary table $1 \mathrm{a}, \mathrm{b}$ ).

We suspect that chlordiazepoxide did not affect the incidence of pneumonia as it is used in the treatment of alcohol dependence and we adjusted for this factor; hence the impact of chlordiazepoxide was dwarfed by the underlying disease. When current prescriptions (those issued within 30 days of the pneumonia) were analysed, diazepam, temazepam and zopiclone were associated with a higher risk of pneumonia; however, lorazepam was not. Nonetheless, the point estimate for the effect of a current prescription of lorazepam on the incidence of pneumonia remained above one and lorazepam was associated with 
increased mortality when we focused on chronic users of the drug (see online supplementary table 1b). Analysis of the longterm mortality data showed a similar pattern of increased mortality for each benzodiazepine. However, zopiclone did not affect mortality in the primary analysis, and we suspect that this relates to the low usage of zopiclone in the population of 'cases' though confirmation in future studies is required. Further investigation is required because zopiclone was associated with an increase in long-term mortality following pneumonia in the propensity score matched analysis (see online supplementary table 1c).

The effect of comorbidity on the benzodiazepine-associated change in risk of, and mortality from, pneumonia may be explained by the influence of cumulative disease processes outweighing the effects of the drug. Another explanation is that inflammation from comorbid diseases influences the expression of the $\mathrm{GABA}_{\mathrm{A}}$ receptor, the putative immune target for benzodiazepines. We have recently observed that certain inflammatory cytokines and stimuli reduce $\mathrm{GABA}_{\mathrm{A}}$ receptor expression on alveolar macrophage (Sanders et al, unpublished observations). A reduction in expression of the receptor target, by comorbid inflammation, would be expected to reduce the immune effects of benzodiazepines as we have observed.

Our findings are complemented by some previous studies. The increase in risk of pneumonia is similar to a previous study by Knol et $a l^{30}$ which recorded a 60\% increased risk during the first week of exposure to 'anti-psychotic' medication. Vergis et al ${ }^{31}$ showed that the use of 'tranquilisers' increased mortality from pneumonia in patients in long-term care. Using a retrospective cohort study design, Hak et $a l^{12}$ followed up 229 people over 60 years of age with pneumonia over a period of 2 years and found that the use of benzodiazepines and/or antidepressants increased the risk of pneumonia by $89 \%$. The same group performed a similar study in over 80 -year-olds which showed a conflicting result; benzodiazepine and/or antidepressant use was not associated with hospital admission or death in this cohort with pneumonia after multivariable analysis. ${ }^{13}$ These two contrasting findings from the same group ${ }^{12} 13$ may be consistent with our observations, as elderly patients likely have greater comorbidity, reducing the impact of benzodiazepines on mortality (table 5). In contrast, our finding that patients with less comorbid disease are vulnerable to benzodiazepine-induced susceptibility to pneumonia are in line with effects on a relatively younger population. ${ }^{12}$

Further studies are needed to confirm our findings. Prospective cohort studies are warranted to understand the impact of benzodiazepines on outcomes from infection. Further studies should also confirm the safety of other drugs, such as the antiepileptic medication topiramate that targets $\mathrm{GABA}_{\mathrm{A}}$ receptors. ${ }^{32}$ Randomised controlled trials are potentially difficult given the lack of therapeutic alternatives at present. However, benzodiazepines that are selective for $\mathrm{GABA}_{\mathrm{A}}$ receptor subtypes are under development ${ }^{33}$ and may have a superior immune profile to the current non-selective drugs (Sanders et al, unpublished observations). In intensive care, where patients are at high risk of infection and large doses of benzodiazepines are used, it is possible to randomise patients to sedation with a GABAergic or non-GABAergic sedative ${ }^{8-10}$ and randomised controlled trials should be considered in this context.

\section{CONCLUSIONS}

Benzodiazepines and zopiclone are commonly prescribed medications that have significant immune effects. Our data herein suggest that they may increase both the risk of and mortality from pneumonia. This is consistent with data from clinical trials ${ }^{8-10} 34$ and concerns expressed over the intensive care unit effects of these drugs leading to movement away from benzodiazepine sedation. ${ }^{35}$ Nonetheless, given the widespread use of benzodiazepine drugs, further studies are required to evaluate their safety in the context of infection.

Acknowledgements RDS devised the hypothesis. All authors took part in study design and interpretation. EO and PM performed the analyses. PM had full access to all of the data in the study and takes responsibility for the integrity of the data and the accuracy of the data analysis. RDS and EO wrote the paper with input from RH and PM. All authors approved the manuscript. We thank Christopher JP Smith, Division of Epidemiology and Public Health, University of Nottingham, for the initial data extraction. RDS is supported by the Medical Research Council, Swindon, UK (RDS: G0802353). RH is supported as the GSK/British Lung Foundation Chair of Respiratory Epidemiology. RDS has received an honorarium from Hospira, Lake Forest, Illinois, USA, for speaking on the immune effects of sedative agents at the Canadian Society of Anesthesiologists meeting 2011. There is no ongoing relationship. There was no industrial involvement in this study.

Funding Funding came from departmental resources. RDS is supported by the Medical Research Council, Swindon, UK (RDS: G0802353). RH is supported as the GSK/British Lung Foundation Chair of Respiratory Epidemiology.

Competing interest All authors have completed the Unified Competing Interest form at www.icmje.org/coi disclosure.pdf (available on request from the corresponding author) and declare: no support from any organisation for the submitted work; RDS received an honorarium for a talk at the Canadian Society of Anaesthesiologists from Hospira in the previous 3 years (there is no ongoing relationship and there was no industrial involvement in this work); no other relationships or activities that could appear to have influenced the submitted work.

Ethics approval SRC (11-010R).

Provenance and peer review Not commissioned; externally peer reviewed.

\section{REFERENCES}

1 Woods JH, Katz JL, Winger G. Benzodiazepines: use, abuse, and consequences. Pharmacol Rev 1992;44:151-347.

2 Gleason PP, Schulz R, Smith NL, et al. Correlates and prevalence of benzodiazepine use in community-dwelling elderly. J Gen Intern Med 1998;13:243-50.

3 Sanders RD, Hussell T, Maze M. Sedation \& immunomodulation. Crit Care Clin 2009;25:551-70, ix

4 Laschi A, Descotes J, Tachon P, et al. Adverse influence of diazepam upon resistance to Klebsiella pneumoniae infection in mice. Toxicol Lett 1983;16:281-4.

5 Galdiero F, Bentivoglio C, Nuzzo l, et al. Effects of benzodiazepines on immunodeficiency and resistance in mice. Life Sciences 1995;57:2413-23.

6 Huemer HP, Lassnig C, Nowotny N, et al. Diazepam leads to enhanced severity of orthopoxvirus infection and immune suppression. Vaccine 2010;28:6152-8.

7 Sanders RD, Myles PR, Hubbard R, et al. Benzodiazepines Increase Mortality from Pneumonia: Role of GABAergic Signalling. Anesthesiology 2011:A765.

8 Pandharipande PP, Pun BT, Herr DL, et al. Effect of sedation with dexmedetomidine vs lorazepam on acute brain dysfunction in mechanically ventilated patients: the MENDS randomized controlled trial. JAMA 2007;298:2644-53.

9 Pandharipande PP, Sanders RD, Girard TD, et al. Effect of dexmedetomidine versus lorazepam on outcome in patients with sepsis: an a priori-designed analysis of the MENDS randomized controlled trial. Crit Care 2010;14:R38.

10 Riker RR, Shehabi Y, Bokesch PM, et al. Dexmedetomidine vs midazolam for sedation of critically ill patients: a randomized trial. JAMA 2009;301:489-99.

11 Jakob SM, Ruokonen E, Grounds RM, et al. Dexmedetomidine vs midazolam or propofol for sedation during prolonged mechanical ventilation: two randomized controlled trials. JAMA 2012;307:1151-60.

12 Hak E, Bont J, Hoes AW, et al. Prognostic factors for serious morbidity and mortality from community-acquired lower respiratory tract infections among the elderly in primary care. Fam Pract 2005;22:375-80.

13 van de Nadort C, Smeets HM, Bont J, et al. Prognosis of primary care patients aged 80 years and older with lower respiratory tract infection. Br J Gen Pract 2009;59: e110-5.

14 Lodder J, Luijckx G, van Raak L, et al. Diazepam treatment to increase the cerebral GABAergic activity in acute stroke: a feasibility study in 104 patients. Cerebrovasc Dis 2000;10:437-40.

15 Almirall J, Bolibar I, Balanzo X, et al. Risk factors for community-acquired pneumonia in adults: a population-based case-control study. Eur. Resp. J. 1999;13:349-55.

16 Dublin S, Walker RL, Jackson ML, et al. Use of opioids or benzodiazepines and risk of pneumonia in older adults: a population-based case-control study. JAm Geriatr Soc 2011;59:1899-907

17 Julou L, Blanchard JC, Dreyfus JF. Pharmacological and clinical studies of cyclopyrrolones: zopiclone and suriclone. Pharmacol Biochem Behav 1985;23:653-9.

18 THIN. The health improvement network. London: The Health Improvement Network, 2011. 
19 Hennessy S, Bilker WB, Berlin JA, et al. Factors influencing the optimal control-to-case ratio in matched case-control studies. Am J Epidemiol 1999;149:195-7.

20 Deyo RA, Cherkin DC, Ciol MA. Adapting a clinical comorbidity index for use with ICD-9-CM administrative databases. J Clin Epidemiol 1992;45:613-19.

21 Charlson M, Pompei $\mathrm{P}$, Ales $\mathrm{K}$, et al. A new method of classifying prognostic comorbiditty in longitudinal studies: development and validation. J Chronic Dis 1987:40:373-83

22 Adams J, Ryan V, White M. How accurate are Townsend Deprivation Scores as predictors of self-reported health? A comparison with individual level data. J Public Health Adv Access 2004:27:1-6.

23 Charlson F, Degenhardt L, McLaren J, et al. A systematic review of research examining benzodiazepine-related mortality. Pharmacoepidemiol Drug Saf 2009;18:93-103.

24 StataCorp. Stata statistical software: release 10. College Station, TX: StataCorp LP, 2007.

25 James $\mathrm{D}$, Schinnar $\mathrm{R}$, Warren $\mathrm{B}$, et al. Validation studies of the health improvement network (THIN) database for pharmacoepidemiology research. Pharmacoepidemiol Drug Saf 2007:16:393-401.

26 Macfarlane J, Colville A, Guion A, et al. Prospective study of aetiology and outcome of adult lower-respiratory tract infections in the community. Lancet 1993;341:511-14.

27 Macfarlane J, Holmes W, Gard P, et al. Prospective study of the incidence, aetiology and outcome of adult lower respiratory tract illness in the community. Thorax 2001;56:109-14.
28 Woodhead M, Macfarlane J, McCracken J, et al. Prospective study of the aetiology and outcome of pneumonia in the community. Lancet 1987;1:671-4.

29 Schneeweiss S, Maclure M. Use of comorbidity scores for control of confounding in studies using administrative databases. Int J Epidemiol 2000;29:891-98.

30 Knol W, Van Marum RJ, Jansen PAF, et al. Antipsychotic Drug Use and Risk of Pneumonia in Elderly People. J Am Geriatr Soc 2008;56:661-66.

31 Vergis EN, Brennen $C$, Wagener $M$, et al. Pneumonia in long-term care: a prospective case-control study of risk factors and impact on survival. Arch Intern Med 2001;161:2378-81

32 Bhat $\mathrm{R}$, Axtell R, Mitra $A$, et al. Inhibitory role for GABA in autoimmune inflammation. Proc Natl Acad Sci USA 2010;107:2580-5.

33 Mirza NR, Larsen JS, Mathiasen C, et al. NS1139

(3'-(5-(1-hydroxy-1-methyl-ethyl)-benzoimidazol-1-yl)-biphenyl-2-carbonitr ile), a unique subtype-selective GABAA receptor positive allosteric modulator: in vitro actions, pharmacokinetic properties and in vivo anxiolytic efficacy. J Pharmacol Exp Ther 2008;327:954-68.

34 Pandharipande P, Shintani A, Peterson J, et al. Lorazepam is an independent risk factor for transitioning to delirium in intensive care unit patients. Anesthesiology 2006:104:21-6.

35 Ely EW, Dittus RS, Girard TD. Point: should benzodiazepines be avoided in mechanically ventilated patients? Yes. Chest 2012:142:281-4. 